\title{
A Psicanálise como Paráfrase Política: École Freudienne de Paris e a ETIFicaçáo da Teoria Lacaniana ${ }^{1}$
}

\author{
Nilton Ken Ota ${ }^{2}$
}

\begin{abstract}
RESUMO: Em grande medida, os estudos sobre a constituição do arcabouço teórico do lacanismo têm ocorrido ao largo do exame de sua historicidade. Essa negligência reforça o ocultamento do processo social que levou a produção lacaniana a uma profunda integração entre a formalização e a etificação da teoria. Esse processo não pode ser compreendido sem a contextualização crítica da conjuntura política que cercou a proposta e a existência da École Freudienne de Paris (EFP), fundada por Lacan, em 1964. A estreita convivência com os jovens militantes dos grupos da esquerda extraparlamentar da época, notadamente os maoístas, e a assimilaçáo de suas problematizaçóes fizeram do pensamento lacaniano e da EFP o espaço de objetivaçáo de um discurso movido pela paráfrase política e seus efeitos de engajamento. Este artigo pretende expor as linhas de estruturaçáo político-social dos conceitos forjados por Lacan, em meio à instituiçáo e à consolidação de sua Escola.
\end{abstract}

PALAVRAS-CHAVE: Maio de 68. Psicanálise. Maoísmo francês. Intelectuais. Engajamento.

$\mathrm{O}$ analista faz-se guardião da realidade coletiva, sem sequer ter competência para isso. Sua alienação é redobrada - pelo fato de lhe ser possível escapar dela. (LACAN, 2003c, p. 358).

\section{ENTRE DOIS LEVANTES}

Não fosse por acontecimentos estranhos a maio de 1968, reclusos ao arquipélago freudiano e sua história de cisôes e alianças, certamente não teria sido como materialista que a prosa lacaniana alcançaria, ao fim de um longo período de incubação, a audiência entre os insurretos, muitos deles à espera da revolução e à espreita de seus signos, reunidos nas células e grupos das diferentes correntes comunistas que invadiram a cena política e cultural, desde o início

\footnotetext{
${ }^{1}$ http://dx.doi.org/10.1590/S0101-31732016000400004

${ }^{2}$ Doutor em Sociologia pela Universidade de São Paulo. Pós-Doutor em Filosofia pela Universidade de Sáo Paulo. Pesquisador do Sophiapol da Université Paris Ouest Nanterre La Défense. E-mail: nilton. ota@gmail.com. Este artigo resulta de pesquisa financiada pela Fundação de Amparo à Pesquisa do Estado de São Paulo (FAPESP).
} 
da $\mathrm{V}^{\mathrm{a}}$ República. $\mathrm{O}$ encontro da juventude marxista com o lacanismo em vias de expansão não foi, contudo, espontâneo e livre da ingerência da ortodoxia partidária e seus braços organizacionais. Tampouco se prestou a unificar o que já sonhara o freudo-marxismo francês. ${ }^{3}$ Os eventos que conduziram os enunciados da psicanálise de Lacan para um regime propriamente materialista de validação discursiva estiveram associados à instabilidade da École Freudienne de Paris (EFP), nos seus primeiros anos de existência. Com a irrupção de 68, a afinidade entre o programa lacaniano e a politizaçáo da nova audiência de seus seminários não demoraria a ganhar convergência estratégica. Inventados com o claro objetivo de imprimir uma nova direção às modalidades de ensino e formação analíticas, alguns dos seus dispositivos foram propostos antes das barricadas no Quartier Latin, razão pela qual Lacan teria creditado à sua Escola um 68 antecipado (ROUDINESCO, 1986, p. 481).

Fundada em 1964, após a expulsão de Lacan da International Psychoanalyse Association (IPA), a EFP carregaria a marca da ruptura e refletiria as contradiçôes de uma iniciativa pensada para ser o polo antagônico à lógica hierárquica. Tratava-se de colocar no centro da nova instituição a aporia freudiana a propósito da impossibilidade estrutural de existir qualquer norma imanente ao inconsciente, sobre a qual uma regulação terapêutica pudesse se apoiar. ${ }^{4}$ Liberada dos critérios de certificação prescritos pela IPA, a EFP constituiria, segundo o desejo de seu fundador, o espaço para a assunção da experiência freudiana na figura do próprio analista que, autorizado por sua própria análise pessoal, conduziria o processo de formalização e posicionamento de um saber frente às demandas de satisfação pulsional, tanto no registro individual de um tratamento quanto na dimensão cultural dos imperativos sociais. Saber singular, ainda que transmissível, e material, embora subjetivo. A EFP examinaria seus princípios de funcionamento na própria trajetória da descoberta do inconsciente e, com eles, daria entrada a uma nova geração de analistas e náo-analistas, coadjuvantes da ampliação e, em pouco tempo, da massificação do discurso de um Lacan que, a partir de 1966, com a publicação de seus Escritos, se tornara autor de significativa repercussão editorial.

\footnotetext{
${ }^{3}$ Sobre a vertente do freudo-marxismo na França, cf. Roudinesco (1986, p. 50-87). Entre o póssegunda guerra e o fim do ciclo dos levantes iniciados em 1968, a tentativa mais conhecida, embora pouco sistemática, de reunir Marx e Freud em uma mesma unidade teórica foi a realizada por Louis Althusser (1993).

${ }^{4} \mathrm{O}$ exame paradigmático dessa impossibilidade foi dado por Freud, em um de seus últimos escritos, "Análise finita e infinita", de 1937. (FREUD, 1981a [1937]).
} 
No que concerne à estrutura organizacional da EFP, a abertura aos não-analistas constituía um elemento central de sua identidade e um dos seus princípios mais importantes, descritos no programa apresentado como seu "ato de fundação" (LACAN, 2003b). Desde o início, Lacan procurou inscrever nos quadros da Escola o sinal de uma heterogeneidade cultural cada vez mais pungente e que já se revelava nos círculos próximos ou em estreita interação com a prática psicanalítica. A conjuntura social mostravase extremamente favorável à implantaçáo de suas teses, em especial daquelas voltadas à recomposição das bases de sustentação da doutrina freudiana. Ao contrário dos procedimentos consagrados pela IPA, Lacan havia proposto, em última instância, uma indiferenciação epistemológica entre a "análise pessoal" e o acompanhamento institucional do trabalho clínico, por parte do "didata", a título de certificação da conduta terapêutica como sendo legitimamente a de um psicanalista ("psicanálise didática”). A EFP também suprimiu a exigência de que o "didata" fosse escolhido entre os seus membros. O núcleo institucional deslocava-se definitivamente para fora dos limites de regência do grupo de notáveis ou dos analistas das primeiras geraçóes do lacanismo. Era preciso, portanto, prover a Escola de instrumentos organizacionais capazes de municiar sua renovaçáo, a partir de um afluxo crescente, teórica e doutrinalmente fundamentado.

Nesse sentido, imaginado como peça de articulação de todos os momentos do trabalho na Escola, o "cartel" foi o primeiro dispositivo de generalização do princípio de não-hierarquização dos parâmetros de validação da formação: "pequeno grupo" de três a cinco pessoas animado pelo "MAIS UM", membro designado pelos próprios participantes como o responsável pela "seleção", "discussão" e "destino a ser reservado ao trabalho de cada um", sem que essa eleição lhe encarregasse, em paralelo, o exercício de qualquer função diretiva em uma "hierarquia de cima para baixo", mas, antes, lhe delegando uma função incitativa em "[...] uma organização circular cujo funcionamento, fácil de programar, se firmará na experiência.” (LACAN, 2003b, p. 235-236). O "cartel" seria a expressão programática da introdução de um desequilíbrio nos estados anteriores e entre seus personagens mais célebres, refletido no enfraquecimento das relaçóes de poder sustentadas pela rede de alianças tecida ao longo das divisôes do movimento internacional de psicanálise, das quais a cisão francesa constituiria um dos seus capítulos mais controversos. Doravante, a heterodoxia lacaniana teria que se ater ao espólio de suas batalhas constantes, não mais o das lutas contra a hegemonia da IPA, mas o acumulado nas frentes de expansão de seu ensino, cada vez mais exposto às paixóes políticas 
de uma geração estrangeira ao então modelo aristocrático das Sociedades de Psicanálise. A EFP impunha, assim, a necessária criação de outros dispositivos de formação de analistas, de validação das funções institucionais atribuídas aos seus membros e de critérios de seleçáo dos aderentes.

Instrumento de indexação institucional do saber inconsciente subjacente, em tese, à decisão de uma pessoa em tornar-se analista ao fim de um tratamento, o "passe" foi, sem dúvida, o mais polêmico e original de todos os dispositivos da história do lacanismo. Apresentado em outubro de 1967 em resposta à tendência de fragmentação da Escola e ao descompasso entre o notável avanço teórico, promovido pelas Ciências Humanas, e a rigidez das modalidades de formação analítica, em geral ainda prisioneiras do espírito de possessão mística da clínica, o "passe" instituía o testemunho sobre a análise pessoal, enunciado pelo próprio postulante, como o discurso autorizado a certificar a presença do saber inconsciente. $\mathrm{O}$ dispositivo se orientava pelo duplo processo inscrito na demanda do candidato. De um lado, procurava acolher sua dimensão transferencial, mas de maneira a esvaziá-la de qualquer personalização. $\mathrm{O}$ depoimento deveria ser dado a três "passadores", pessoas indicadas pelo analista do candidato. Estas, por sua vez, relatariam a passagem (ou não) de analisante a analista a um jurado designado pelo conselho da Escola. O conteúdo pulsional envolvido e posto em circulação se atrelaria a uma conversão sublimatória, irrigando as práticas institucionais com uma nova versão do saber psicanalítico. Daí a posterior nomeação do manejo institucional desse duplo processo, "transferência de trabalho", única forma do "ensino da psicanálise" ser transmitido "[...] de um sujeito para outro." (LACAN, 2003b, p. 242). Imediatamente, o "passe” tornouse arena das mais intensas polêmicas e disputas, o que motivou, táo logo aprovado estatutariamente, em 1969, o pedido de demissáo dos primeiros cardeais a deixarem a EFP. Outros os acompanhariam, no decurso de novas crises. Se o "cartel" se mostrara um eficiente mecanismo de mobilização da capacidade de trabalho dos membros e aderentes, o "passe" revelou-se o próprio espaço da política lacaniana. Como dispositivo de assimilação e tradução do engajamento militante dos grupos da esquerda extraparlamentar, o "passe" deslocou o centro de gravitação das relaçóes de poder no lacanismo, ao transferir a força motriz do manejo clínico para um conceito fortemente vinculado a uma formulaçáo sobre a organização institucional, o "desejo do analista." (LACAN, 2003d, p. 277).

Centrada nesse "desejo", que não era um "desejo puro", mas o de "obter a diferença absoluta” em cada tratamento (LACAN, 1998b, p. 260), a EFP iniciava um movimento de diluição da velha hierarquia do lacanismo, sem, no entanto, 
macular os poderes monárquicos de seu fundador. Ao permitir a entrada de pessoas que não haviam se submetido a uma análise, Lacan pretendeu dar à sua Escola a face plebeia dos levantes e amotinados. Para além do anedotário que costuma cercar suas declaraçóes, eram claras as analogias entre o programa da EFP e os valores de base do maoísmo, disseminados na França como o mirante possível de uma revolução vindoura e que maio, enfim, parecia confirmar. Como bem lembrou Roudinesco (1986), não estaria, portanto, descartada a hipótese de Lacan ter se inspirado na doutrina política de Mao Tsé-Tung, embora sem qualquer intenção explícita, enquanto se via no fogo cruzado dos interesses divergentes que atravessavam sua Escola. Do mesmo modo que na revolução cultural chinesa, o procedimento utilizado seria o da organização das massas, em um movimento vindo da base, não espontâneo, o qual forçaria uma depuração das classes dirigentes, acuadas pela imposição de uma "autocrítica". Tudo a partir do corpo doutrinário emanado e conduzido por um "grande timoneiro". No caso da EFP, entretanto, os resultados do "passe" jamais foram pensados e propostos como libertários (ROUDINESCO, 1986, p. 482), apesar dos efeitos do novo dispositivo se assemelharem aos da revolução maoísta. A instituição lacaniana tomava a recomposição das forças internas como uma necessidade de estrutura do inconsciente. Por isso, o acento ético das proposiçóes da EFP. Cerca de quinze anos após suas primeiras elaboraçóes sobre a "ética da psicanálise" (LACAN, 1997), Lacan projeta para sua Escola os anseios - e as angústias - de uma teoria que evoluiu, ao longo de duas décadas, sempre no sentido de uma unificação entre um formalismo crescente e uma subjetivação de seu discurso, cuja injunção somente poderia conclamar o engajamento militante dos mais radicais, justamente aquele que tomava propulsão através do esvaziamento das vivências anteriores. Não sem razão, Lacan o encontraria entre os maoístas das classes abastadas, formados nas grandes escolas parisienses e espiritualizados pela verdade conceitual incognoscível, todavia pulsante no ato que teria instituído a revolução chinesa.

\section{A “ÉTICA DA PSICANÁLISE” À SOMBRA DA ESTRUTURA E À LUZ DA POLÍTICA}

[...] as "abstraçóes" da Psicanálise são exatamente os autênticos conceitos científicos de seu objeto, na medida em que, enquanto conceitos científicos de seu objeto, elas contêm em si o índice, a medida e o fundamento da necessidade de sua abstração, ou seja, a própria medida de sua relação com o "concreto", logo, a sua própria relação com o concreto de sua aplicação, comumente chamada de prática analítica (a cura). (ALTHUSSER, 2000, p. 68). 
Antes de ter conseguido lastrear materialmente seu campo de objetos e conceitos, a psicanálise lacaniana teria partilhado a mesma órbita de pertinência epistemológica da Antropologia lévi-straussiana ${ }^{5}$ e de todas as ciências orientadas pelo desenvolvimento metodológico da Linguística contemporânea. Daí a precisa localização althusseriana de seu estatuto científico no que definiria, em última instância, a ordem da cultura, as "leis formais" do "Simbólico" (ALTHUSSER, 2000, p. 64). Assim como toda ciência estruturalista, a psicanálise de Lacan garantiria sua cientificidade por meio da "[...] definição da essência formal de seu objeto, condição de possibilidade de toda a aplicação prática, técnica, aos seus próprios objetos concretos." (ALTHUSSER, 2000, p. 68). Sumária identificação das suas fronteiras no interior do espaço instituído por uma objetivação formal engendrada por conceitos esvaziados de sentido e, portanto, puramente instrumentais e operatórios. A cientificidade poderia com facilidade ser tomada por sua esfera técnica, um dos pontos que mais denunciaria o conteúdo ideológico do estruturalismo, segundo seus críticos.

Ao contrário das ciências centradas na grade relacional dos pares diacríticos de uma estrutura, as teorias históricas apresentariam seu universo de questôes, objetos e conceitos sob a regência das transformações e na posição sagital dos eventos e suas contingências; conhecimento perspectivo, porque datado e associado a uma temporalidade teoricamente instável. De um lado, um materialismo extraído da recorrência formal das relações opositivas, apenas apreensível na sincronia da duração; do outro, um materialismo inscrito no movimento processual dos acontecimentos e na direçáo do tempo sucessivo. A configuração francesa do estruturalismo envolveu esse debate e o reposicionou nos termos de uma politização crescente. Se a geração de Lévi-Strauss teve que justificar o lugar da ação política e da temporalidade histórica, em resposta ao maciço e constante ataque dos $\operatorname{críticos}^{6}$, o reconhecimento intelectual alcançado pelo estruturalismo, na segunda metade dos anos 1960, não se resumiu, no entanto, à ocupação de postos nas mais prestigiadas instituiçóes de ensino e pesquisa ou ao sucesso editorial logrado por alguns de seus autores (DOSSE, 2007).

Fortalecidos pelas vanguardas estéticas, público cativo de suas teorias, os grupos estruturalistas, por intermédio, sobretudo, de suas revistas, perfilaram-

\footnotetext{
${ }^{5}$ Existe um universo extenso de estudos dedicados a essa questấo, recentes e antigos, os quais remontam ao contexto da hegemonia do estruturalismo na cena intelectual francesa dos anos 1960. A influência lévi-straussiana sobre Lacan pode ser observada com detalhes no texto de 1952, conhecido como "O mito individual do neurótico". Cf. Lacan (2008b).

${ }^{6}$ Sem dúvida, a polêmica mais intensa foi travada com Sartre. Cf. Sartre (1960) e Lévi-Strauss (1997).
} 
se como agentes de politização de uma espécie de programa coletivo nãodeclarado. De fato, subjacente a essa politização, interesses específicos e de disputa no campo literário e entre os próprios estruturalistas. Muito mais do que evento instituidor, maio de 68 foi aqui, antes de tudo, um "recurso de diferenciação" ou uma "matriz de significação" (GOBILLE, 2005) entre os grupos, tendo na politização uma estratégia de "requalificação" (MATONTI, 2005) do estruturalismo, donde a inconstância induzida pelas controvérsias sem fim, seu dinamismo teórico animado pela busca permanente de inovação. Ao invés da "economia da paciência" que caracterizaria toda "acumulação de um capital simbólico", a prevalência das "reviravoltas teóricas" determinadas pela miragem estruturalista das revoluçóes estética e política sob a salvaguarda de uma mesma forma expressiva (GOBILLE, 2005, p. 94).

A confluência entre a vanguarda estruturalista e a política instaurada pela sublevação de 68 significou tanto a generalizaçáo de uma sorte de imperativo materialista e, consequentemente, o desencadeamento de uma "crise na teoria" (MATONTI, 2005), quanto um momento de ebulição intelectual e de ampla renovação metodológica nas Ciências Humanas. Não foram poucas as ambiguidades acarretadas nesse cenário de intensificações cruzadas de processos regionais. A totalização correspondente sugeria uma recomposição dos campos de saber, com base em um alinhamento heterogêneo das teorias. Em outras palavras, ainda que a autonomia relativa de cada um dos campos fosse preservada, a configuração de seu conjunto implicaria uma posição transversal reservada à politização. Assim, um duplo movimento recortaria os campos, em níveis e dimensôes distintas, o que se revelou pela profusão semântica de uma nova economia dos discursos. Sua materialidade era, a um só tempo, prática e estratégica, e cada vez menos simbólica e sistêmica. As operaçôes teóricas de redundância formal como modo de representaçáo da cientificidade de um saber materialista perdem rapidamente o seu apelo de vanguarda. Em contrapartida à série vinculante consagrada por Althusser, entre objeto, conceito e aplicação, o delineamento de um materialismo político, cujos fundamentos, contudo, estariam distantes da canônica do valor-trabalho, encontrando seu espaço na ordem dos efeitos de um poder essencialmente indeterminado. Da parte da psicanálise lacaniana, parceira de longa data da defesa do primado da sincronia e que havia se beneficiado da expansão estruturalista desde o seu princípio, a preocupação com a formalização clínica permanecia entre suas prioridades, concebida como elemento imprescindível da construção de uma teoria da transmissão objetiva do inconsciente, sem a qual a descoberta freudiana ficaria à mercê dos rituais de ocultismo, muitas vezes exercidos de modo velado e 
sob a proteção dos procedimentos tradicionais de certificação institucional. Até a fundação da EFP, Lacan não havia atribuído qualquer centralidade à dimensão material dos fenômenos clínicos, estes ainda categorizados com o recurso da tríade "imaginário, simbólico e real", painel teórico de inspiração estruturalista que seria profundamente alterado a partir de 1964, ano, não por acaso, também de sua invenção conceitual mais substantiva, o "objeto $a$ ".

Novamente, a história política encontra e atravessa o movimento psicanalítico francês, sem, entretanto, intervir diretamente em seus destinos. A convergência entre a politização do estruturalismo e a reorientação deflagrada pela fundação da EFP ganhou figuração por meio dos novos dispositivos de formação e da materialidade objetal dos fenômenos clínicos, doravante no centro da problematização teórica do lacanismo. A permeabilidade da EFP permitia e estimulava a entrada do engajamento militante, mas para subvertêlo, diferentemente da tática adotada pelos grupos de vanguarda estética, os quais, impulsionados pela intensificação política da teoria, disputariam entre si as letras de crédito de uma mobilização social crescente. Os capitais acumulados pelo estruturalismo, ao longo de quase vinte anos de reinado, se dispersariam com rapidez em controvérsias entre intelectuais que, caricaturalmente, pareciam mimetizar a altivez de espírito retida nas imagens míticas das assembleias e comitês revolucionários. Assim, esses intelectuais buscavam repetir a tradicional impostação perlocutória da representação política inaugurada pelo republicanismo francês. Em 68, eles seriam definitivamente desvalidos de atualidade crítica. Na EFP, essa declinação da autoridade intelectual atingia os mais experientes, antigos parceiros de Lacan, entre os quais aqueles que estiveram ao seu lado durante as cisóes e rupturas que desenharam o rosto da secessão na história do movimento psicanalítico internacional. É nesse sentido que o "passe" não pode ser dissociado do contexto político que antecedeu os levantes de 68. Contragolpe tático de Lacan, aliado aos poderes que se galvanizavam na juventude e seus novos modelos de ação, o "passe" se revelou, desde a sua primeira formulação, um instrumento de assimilação das paixões políticas e de renovação da doutrina freudiana; ele foi a expressão organizacional do materialismo lacaniano em vias de construção, ao preço do sacrifício de antigas fidelidades. Teoricamente, tratava-se de dar consequências aos trabalhos do final da década de 1950, mediante a formalização da estrutura da repetição inconsciente.

A repetição havia sido eleita por Lacan como fio condutor de seu seminário de 1959, investigaçáo detida nas incidências da conduta do analista 
sobre a transferência, donde sua reflexão sobre a "ética da psicanálise" e seu inusitado programa de leitura, que incluía uma interpretação sui generis de um texto que Freud havia se recusado a publicar, visto ainda hoje por muitos especialistas como pré-psicanalítico, o "Projeto para uma psicologia científica" (FREUD, 1985e [1895]). Árida tentativa de explicar a funcionalidade neurobiológica do psiquismo, o Projeto teria, para Lacan, pressagiado a intuição freudiana sobre a "pulsão de morte", força tendencial vivida como exterior à pessoa, conceito forjado apenas em 1920, a partir da observação clínica dos sintomas compulsivos (FREUD, 1985c [1920]). Entre seus signos, convençóes e um esboço de psicopatologia sem sustentação clínica significativa, o ensaio indicaria os caminhos para uma teorização condizente com as exigências da formação analítica, porque Freud nele teria deduzido, ainda que com o recurso de premissas totalmente especulativas, a posição do inconsciente no dinamismo estrutural do aparelho psíquico (LACAN, 1966c). Em outras palavras, efeito de uma intervenção singular, com repercussóes sobre a totalidade do sistema, base para a tese lacaniana do inconsciente como derivação de uma decisão fundacional de um sujeito hipotético, formalmente dedutível e, portanto, desprovido de qualquer interioridade psicológica. No Projeto, o sistema neurobiológico do psiquismo seria totalizado pelo encontro com uma exterioridade plena, um "objeto absoluto" (das Ding), inassimilável pelos mecanismos mnêmicos e de representação, sem qualquer inscrição no sistema, mas cujo encontro deixaria trilhamentos de memória, vias de acesso, tanto ao prazer quanto à angústia. Por isso, a recorrência de uma estranheza sem imagem (Fremde) (LACAN, 1997, p. 69). O sujeito estaria destinado a fazer uma espécie de busca metafísica desse objeto, como restituição impossível de uma perda, transcrição narrativa do que o Projeto esquematizou da circulação libidinal e do impulso que move, a um só tempo, dois extremos, a repetição compulsiva e a satisfação sublimatória.

No seminário de 1959, Lacan retoma o Projeto e dele retira o corolário metapsicológico da presença do analista. Desde entáo, o lacanismo passará a compreender a transferência como instauração dessa presença no inconsciente e o analista enquanto uma de suas formaçóes, o que fez com que a circunscrição da psicanálise passasse à esfera de uma conduta particular, a de uma "ética" que deveria lhe ser exclusiva. O programa de etificação da teoria ainda esperaria alguns anos para ser iniciado pela EFP. Porém, seus alicerces já estavam sendo preparados desde muito, a despeito dos rumos que viria tomar o lacanismo. Cerca de dez anos antes dos motins no Quartier Latin, o redirecionamento teórico proposto implicava grandes transformações, todas 
condicionadas ao futuro próximo. Primeiramente, a problematização sobre a ética não recaía apenas sobre a clínica e seus achados, mas, sobretudo, induzia sua integração à perspectiva metapsicológica, mobilizando toda construção conceitual no sentido de conferir-lhe um engajamento e uma potência prática que não fosse somente a prevista pelo saber freudiano e aquela delimitada pelas Sociedades de Psicanálise. Por sua vez, a extensão do impacto dessa disposição intelectual sobre a comunidade psicanalítica conflagraria, em breve, a convocação de suas ortodoxias, prevenidas do levante que se anunciava com a crescente necessidade, percebida e defendida pela corrente lacaniana, de uma ampla revisão das modalidades de formação dos analistas e de transmissão do conhecimento clínico. Consequentemente, a terceira transformação estaria ligada a uma interrogaçáo ampla a respeito de qual seria a ordem institucional capaz de refletir a realidade levantada pela "ética da psicanálise", com todos os seus impasses, antinomias e contradições. Realidade psíquica e social, como haviam demonstrado as próprias escolas psicanalíticas, as quais, cerradas contra a história, terminavam por explicitar o conteúdo latente de sua ideologia, o mesmo destino pulsional que Freud detectara nas religióes (FREUD, 1985a [1927]). Nesse momento do lacanismo, a teoria dispunha-se em território subordinado à prática clínica, ainda sob a influência soberana do freudismo clássico, contudo, cada vez mais sensível à floração de novas ideias e tolerante com os efeitos inesperados que elas certamente estariam em condiçóes de produzir. Sua etificaçáo foi desencadeada pela expulsão de Lacan dos quadros da IPA, em 1963. A partir desse episódio e, em especial com a EFP, a teoria lacaniana transforma-se em planta arquitetônica e plataforma de lançamento dos planos doutrinários de seu mestre, dos lances de expansão e conquista, dos projetos de agremiação de militantes e profissionais do "social", da prospecção de alunos e aderentes por meio dos seminários. Nos dias da mais aguda crise institucional do lacanismo, o postulado programático da "ética" encontrou um operador clínico, o "desejo do analista" (LACAN, 1998b, p. 17; LACAN, 2003d, p. 277), e a prova material de sua eficácia, o "objeto $a$ ".

\section{O MATERIALISMO LACANIANO DO “OBJETO $a$ ”}

O movimento lacaniano deve à "excomunhão"7 de Lacan a proveniência de um acontecimento de natureza totalmente teórica. A substituição do tema de seu seminário, dedicado originalmente aos "nomes-do-pai”, interrompido

\footnotetext{
${ }^{7}$ Para reproduzir o mesmo termo que Lacan usou para dar uma significação spinoziana ao episódio de sua expulsão da IPA, em 1963. (LACAN, 1998b, p. 11).
} 
após sua primeira sessão, implicaria uma intensificação dos seus esforços de afiançar cientificamente o saber inconsciente, todavia, a partir de outras estratégias e recursos. Retomado em janeiro de 1964, já sob a cobertura dos "conceitos fundamentais da psicanálise", o seminário daria ocasião ao início de uma verdadeira política da subjetivação material do inconsciente, que acompanhará o lacanismo até a dissolução da EFP, em 1980. Se Lacan havia consagrado seu programa estruturalista sob o lema do "retorno a Freud", tratava-se, agora, de submeter os fundamentos da psicanálise sob a interrogação da objetividade que lhes seria constitutiva e que, a despeito do desconhecimento demonstrado pelos próprios analistas em relação ao "núcleo do real" de sua prática, definiria materialmente a eficácia clínica. $\mathrm{Na}$ versão original do seminário, Lacan propunha retomar a estrutura da angústia, trabalhada no ano anterior, com base em sua análise topológica, abordagem que lhe permitiria incluir tanto a questão da constituição do sujeito pela dialética da "alienação" e "separação" do "Outro" (LACAN, 1998b) quanto a pluralidade da função normativa que Freud havia restringido à figura uníssona do pai. Em ambas, uma mesma operação, largamente disseminada nos anos subsequentes, dava novo estatuto e centralidade a um velho conceito do freudismo, o “objeto parcial” (FREUD, 1985b [1927], 1985f [1905]), cuja trajetória concentra os momentos de inflexão do ensino de Lacan. De "objeto perdido", porque coligado ao absoluto (das Ding), segundo a interpretação do Projeto, passando pela sua imagem encobridora sob o amor transferencial, decifrado na estrutura da angústia como "causa do desejo" até, nas formulaçóes mais avançadas, tornar-se o "resto impossível de simbolizar", o conceito ganhou nome próprio e batismo tipicamente lacaniano, o "objeto $a$ ". Sua significação oscilante encarna a prerrogativa epistemológica que Lacan pretendeu lhe dar, ao longo dos anos.

Além de todas as variaçôes existentes sob o conceito freudiano, o “objeto $a$ " também designa o seu oposto. O objeto freudiano espelhava os limites imanentes da satisfaçáa pulsional; o lacaniano os estende até o ponto de seu aterramento em um vazio topológico. Pela via de uma regressão ao "tempo lógico" da "fantasia fundamental", Lacan (1966b) extrai o "objeto a" como posiçáo original do sujeito. A fantasia decifrada por Freud como hipótese do analista e construção do paciente assume (FREUD, 1985d [1919]), na teoria lacaniana, materialidade passível de uma ciência. O sujeito se constitui como objeto do "desejo do Outro", sendo essa a sua posição constitutiva, recalcada, inconsciente e repetida, cuja prevalência pulsional servirá de moldura gramatical para cada satisfação parcialmente alcançada. A 
fantasia transforma-se no "núcleo do real" da experiência analítica. Por isso, a identidade do conceito de "objeto a" se consolida através de uma espiral nominalista e sua extensão é determinada por um mesmo vazio topológico. A última sessão do seminário de 1962-1963 já havia dado indicaçôes claras desse percurso, contudo, para qualificar o "pai” como aquele que realizaria a operação fantasmática que Lacan atribuirá ao analista: "Ao contrário do que enuncia o mito religioso, o pai não é causa sui, mas é o sujeito que foi longe o bastante na realizaçáo de seu desejo para reintegrá-lo em sua causa, seja ela qual for, para reintegrá-lo no que há de irredutível na função do $a$ [objeto $a$ ]. ” (LACAN, 2005b, p. 365-366).

Antes de sua expulsão e ainda sem projetar no "objeto $a$ " a função estratégica implantada posteriormente pelo "passe”, Lacan preconizava como horizonte de sua "ética" a superação da estrutura da angústia pela afirmação dos poderes da transferência adequadamente manejada. A transposição da angústia teria incidência sobre a posição do sujeito na fantasia, visto que ambas seriam estruturalmente homólogas entre si. E a possibilidade da intervenção analítica teria a ver com o próprio vazio topológico do "objeto $a$ ". Ao ser nomeado, esse vazio seria deslocado, fixando-se no analista, o qual, por sua vez, assumiria a posição desse objeto. A transferência lacaniana equivaleria à atualização fantasmática. No seminário de 1962-1963, da nomeação simbólica dependia teoricamente a eficácia do tratamento ["só há superação da angústia quando o Outro é nomeado" (LACAN, 2005b, p. 366)], tese confirmada pela primeira e única sessão do seminário interrompido ["a transferência como o que não tem Nome no lugar do Outro" (LACAN, 2005a, p. 87)]. Daí a defesa de que o "desejo do analista" devesse ser encarnado por "[...] aquele que, minimamente, não importa por qual vertente, por qual borda, tenha feito seu desejo entrar suficientemente nesse $a$ [objeto $a$ ] irredutível para oferecer à questão do conceito de angústia uma garantia real.” (LACAN, 2005b, p. 366). Lacan enfatizaria o paradoxo existente nas exigências que acompanhariam o reconhecimento de um analista: de um lado, seu desejo "[...] deve não apenas compreender, mas transpor a própria fantasia que o sustenta e o constrói” (2005b, p. 359), $\mathrm{e}$, do outro, que não abdique da interrogação sobre os destinos da pulsão depois de feita essa travessia. Contudo, não houve, até o "passe", qualquer mecanismo que pudesse dispor essa dimensão ética em um "mais além da análise". Em outras palavras, por dependerem da passagem pelo "ciclo", em sua "totalidade", do final de um tratamento, e isso por "várias vezes", as qualidades que fundamentam a escuta analítica somente poderiam encontrar na Escola o lugar da "elaboração" (durcharbeiten) de que falava Freud. A "psicanálise 
didática”, consolidada pela IPA como posto certificador do saber inconsciente na formação e ensino, tornava-se o nome institucional dessa "elaboração" (LACAN, 1998b, p. 258). Após a "proposiçấo de 9 de outubro de 1967" (LACAN, 2003f), redigida para ser o documento de referência do "passe", o final de análise passaria a ser teorizável sob a condição da "transferência de trabalho" na Escola, elevada, mediante seus mecanismos de engajamento, à garantia da transmissão do saber inconsciente. $\mathrm{O}$ materialismo lacaniano do "objeto $a$ " era, sobretudo, fruto da política do "passe". Internamente, ele propiciou a supressão do ponto de fuga que conferia perspectiva ao conjunto das relaçóes mantidas sob a Escola, recodificando os interesses e os capitais de seus membros e aderentes. Ao indicar para a dispersão do poder dos veteranos, o "passe" redefiniu as coordenadas de acesso à instituição lacaniana de ensino.

Durante a crise que deu origem à EFP e em seus primeiros anos, a transformação da teoria em discurso por intermédio da etificação dos conceitos era exaustivamente trabalhada por Lacan. $\mathrm{O}$ estilo de sua ressonância e o alcance de suas consequências dependeram, principalmente, do surgimento de um novo tipo de engajamento, programaticamente reservado ao "passe". Se efetivo e, ao contrário do preconizado por Lacan, mobilizado nos espaços não pertencentes à Escola, esse engajamento configuraria uma conduta orientada segundo a normatividade de um regime híbrido, entre a análise e a militância. Externamente, o "passe" apresentava a Escola como uma alternativa à subjetivação militante junto a uma juventude cada vez mais radicalizada e não raro entregue aos imperativos do sacrifício difundidos por muitos grupos de extrema esquerda (SOMMIER, 2008a, 2008b), donde a EFP contemplar com tamanho apuro e energia voluntariosa um dispositivo cuja morfologia lembraria os valores de uma política tão estranha ao lacanismo, como eram os da revolução cultural chinesa e sua metáfora, o maoísmo francês. Contudo, a semelhança formal não era sem propósitos; ela correspondia a uma necessidade estratégica de objetivação social da teoria, cristalizada pelas disputas entre correntes e escolas do movimento psicanalítico e intensificada pela conjuntura política da segunda metade da década de 1960. Daí por que a guinada lacaniana em direção à formalização integral dos conceitos tenha se valido da confluência de dois episódios centrais, a aproximação de Lacan junto aos discípulos de Althusser, na École Normale Supérieure, editores de Les Cahiers pour l'Analyse, e os levantes dos meses de maio e junho de 68, que impactariam de maneira definitiva os rumos que o lacanismo viria a tomar e que deixariam rastros visíveis, ainda hoje, em suas instituiçóes. 
O encontro entre Lacan e os normaliens teve o seu momento decisivo no primeiro número de Les Cahiers pour l'Analyse, de fevereiro de 1966. Com um texto em que a psicanálise era apresentada como uma legítima herdeira do ato fundacional do "sujeito da ciência", Lacan (1998a) reafirma o pressuposto freudiano do recalque originário (FREUD, 1981c [1925], 1981b [1923], 1981d [1915]), mas para subvertê-lo. Assim como a ciência moderna não seria outra senão a inaugurada pela disjunção cartesiana entre saber e verdade (LACAN, 1966a), o sujeito freudiano não seria senáo o sujeito da ciência, aquele dividido estruturalmente por uma causa cujo objeto revelaria ser o mesmo da topologia do recalque originário. E, sendo a verdade a causa em questão, o objeto somente poderia ser o da psicanálise, o "objeto $a$ ". Articulação profícua e condizente com o projeto de Les Cahiers de "[...] contribuir com a constituição de uma teoria do discurso", compreendendo este último como um "[...] processo de linguagem que força [contraint] a verdade." (MILLER, 1966). Ainda segundo Les Cahiers, a epistemologia "[...] se define história e teoria do discurso $d a$ ciência", no singular, porque seu "nascimento", na mesma linha do que concluiu o argumento lacaniano, seria datado e, portanto, identificável. No entanto, diferentemente de Lacan, que convoca a antropologia lévi-straussiana para reconhecer sua localização residual do sujeito como um traço constitutivo da identidade da ciência (LACAN, 1998a, p. 876), Les Cahiers assume posto nas fileiras mais positivistas do estruturalismo francês, ao procurar assegurar seu campo como de "análise" e, de acordo com o significado atribuído ao termo, inscrever-se no discurso que "[...] se reduz a localizar as unidades que se produzem e se repetem, qualquer que seja o princípio que ele assinale nas transformaçóes que trata como tais os conceitos de elemento e de combinatória." (MILLER, 1966). A formalização almejada por Lacan como modalidade de registro e transmissáo do saber inconsciente, contemporânea à materialidade "real" do "objeto a", não seria, portanto, a mesma do horizonte da revista de dar fundamentação epistemológica a "[...] todas as ciências de análise" (MILLER, 1966):

O objeto da psicanálise [...] não é outro senão aquilo que já expus sobre a função que nela desempenha o objeto $a$. O saber sobre o objeto $a$ seria, então, a ciência da psicanálise?

Essa é precisamente a fórmula que se trata de evitar, uma vez que esse objeto a deve ser inserido, já o sabemos, na divisáo do sujeito pela qual se estrutura, muito especialmente, e foi disso que hoje tornamos a partir, o campo psicanalítico. 
Eis por que era importante promover, antes de mais nada, e como um fato a ser distinguido da questão de saber se a psicanálise é uma ciência (e se seu campo é científico), exatamente o fato de que sua práxis náo implica outro sujeito senão o da ciência. [...]

$\mathrm{O}$ ponto em que encontrei vocês hoje, por ser aquele em que os deixei no ano passado - o da divisão do sujeito entre verdade e saber - é para eles [psicanalistas] um ponto conhecido. É aquele a que Freud os convida, sob o apelo do Was Es war, sol Ich werden, que retraduzo, mais uma vez, para acentuá-lo aqui: lá onde isso estava, lá, como sujeito, devo [eu] advir. (LACAN, 1998a, p. 877-878).

Nos primeiros anos da EFP, tratava-se de imprimir à doutrina lacaniana uma direção teórica que erguesse barreiras contra o revisionismo psicanalítico, do qual Freud supostamente já havia sido vítima. Lacan encontrou no grupo normalien a interlocução oportuna para uma projeçáo conceitual mais incisiva, o que, certamente, justifica a qualificação desse momento como sendo o de uma "reformulação lógica" de seu ensino (ROUDINESCO, 1986, p. 423). Todavia, antes de ser propriamente lógica, a política de formalização do saber inconsciente se sobrepunha, em um círculo de apoios recíprocos, à divisão estruturalista do sujeito, ao materialismo do "objeto $a$ " e aos corolários da "ética da psicanálise”. Por isso, as inúmeras transiçôes entre regiôes epistemológicas inconciliáveis, as mais extravagantes combinaçóes de enunciados, o imbróglio produtivo de categorias anacrônicas. A rigor, o método lacaniano encontrava correspondência com os princípios estéticos da composição de vanguarda. Sua preocupaçáo era antes expressiva que explicativa, sua linguagem mais discursiva do que argumentativa, sua racionalidade mais analógica do que lógico-dedutiva. Entretanto, essa conduta de bricoleur, ao contrário daquela que caracterizará boa parte da próxima geração de intelectuais, almejava o reconhecimento científico e nutria-se de um realismo estratégico sem paralelo entre seus contemporâneos. ${ }^{8}$ Nesse particular, os motins de 68 condensaram

\footnotetext{
${ }^{8}$ Da geraçăo de Sartre, mas diferentemente dele, Lacan assumiria abertamente a polêmica com a juventude mobilizada, conformando uma performance que procurava dissociar sua figura de seu discurso, o que, obviamente, somente reforçava ainda mais a unificação entre eles. Tal estratégia lhe garantia uma reserva em relação à intensa movimentação contestatória, sem a qual, como havia acontecido com alguns de seus companheiros de geraçáo que se aproximaram explicitamente dos grupos militantes, seu trabalho e seu discurso seriam facilmente tomados como antigos e superados: "Eu sou liberal, como todo mundo, apenas na medida em que sou antiprogressista. Só que estou metido em um movimento que merece ser chamado de progressista, pois é progressista em ver fundamentar-se o discurso psicanalítico, na medida em que este completa o círculo que poderia, talvez, permitir a vocês situarem exatamente aquilo contra o que se revoltam." (LACAN, 1992, p. 197).
} 
a heterogeneidade dos registros do lacanismo, em um ponto de emanação vertical, o qual objetivava sua enunciação teórica e a convertia em ato de fala, gesto do conceito na tribuna da história. A constelação contestatória empurraria o pensamento francês a uma performatividade generalizada, a psicanálise de Lacan a uma inflexão teórica e, com a EFP, a um impasse político. A partir de 68, a integração entre formalização e etificação da teoria, no costado da materialidade do "objeto $a$ ", deparou-se com a eficácia da emissão modulatória do próprio discurso lacaniano. Sob a fraseologia marxista-leninista que preenchia as ruas e dava eco às paixóes militantes, os amotinados cativavam outras línguas, tornavam-se cidadãos de outras nacionalidades utópicas. E assim faziam com que a irrupção dos eventos assumisse a forma intuitiva de uma convergência inaudita. Melhor ainda, confluência de estratégias e deflagração do imaginário revolucionário das comunas proletárias e plebeias, da liberação do inconsciente na história.

\section{Maio de 68 E a paráfrase Maoísta do “PASSE”}

Como conclamamos ao sequestro?

Quando a greve é desencadeada pelos sindicatos ou, por algum motivo, há um movimento de massa. Quando estamos cansados de esperar, de nos curvarmos ao chefe, a raiva aumenta; Passamos, então, à ação: a palavra de ordem "sequestro", lançada firmemente, deve imediatamente ser seguida por sua realização, caso contrário a tensão pode baixar.

- [...] depois do mês de trabalho político, há uma Assembleia de trabalhadores. O sindicalista toma a palavra; ele é vaiado. Um camarada toma a palavra, é aplaudido; ele propóe o sequestro, é aplaudido. Mas ao propor o sequestro, perde tempo se justificando sem ousar dizer claramente "vamos, sequestremos", e por fim as pessoas se desmobilizam;

- É preciso ser mais vigilante em relação a alguns delegados que tentam sempre sabotar o movimento: "você náo tem o direito de ir às outras seçóes de trabalho". Face a isso, não nos intimidemos, vamos agir rapidamente, nós contamos com a ajuda dos estudantes para popularizar o sequestro;

- Devemos dar muita importância para essa forma de luta dita "ilegal", explicando às massas que não é apenas uma luta reivindicativa, mas, antes de tudo e sobretudo, a política do povo: da resistência proletária e que ela não é senão uma etapa na revolução. (BIBLIOTHĖQUE DE DOCUMENTATION INTERNATIONALE CONTEMPORAINE. Fonds Gauche Prolétarienne. F delta rés 576 3/3/2. Tradução nossa). 
A mobilização soixante-huitarde evocava a tradição histórica da ação direta, cuja versão parisiense daqueles dias de maio se revelou tão modulatória quanto o era o discurso lacaniano, no contexto do movimento psicanalítico. Â exceção dos instrumentos enraizados no âmbito prático do "social", campo de tratamento das desigualdades que podem ameaçar a coesão da sociedade (DONZELOT, 1994), naquela época também submetido à prova da radicalização política, a conversão militante e o deslizamento do engajamento em direção às fronteiras de classe tornaram-se náo apenas possíveis, mas também estimulados, invadindo as normas dos grupos e instilando na subjetividade o teor místico das fontes axiológicas. Sob o primado da ação direta, os dispositivos "gauchistas" encampavam os valores estratégicos da intensificação subjetiva, a despeito da constante e persistente influência da estrutura normativa do Partido Comunista Francês até entre os grupos que negavam a sua legitimidade, como eram as correntes maoístas. Através da imagem de mobilizaçáo das massas, eram disseminados o imperativo militante de aprofundamento das convicçóes e a imposição de um aparato de rastreamento de seus sinais comprobatórios. Nada muito distinto do que haviam inventado os partidos de esquerda, tanto por meio de suas redes de sociabilidade e alistamento (SAWICKI; LEFEBVRE, 2006) quanto de seus "laboratórios do eu" na constituição do "sujeito comunista" (PUDAL; PENNETIER, 2002, 2014). Mesmo nas açóes refratárias às estratégias de passado bolchevique, a imagem que unificava os engajamentos e autorizava suas palavras de ordem continuava a ser a das massas mobilizadas para a revolução. Foi assim com as formulaçóes e debates sobre os sequestros de capitalistas e executivos das grandes empresas, planejados e propagandeados pela Gauche Prolétarienne, principal grupo maoísta da esquerda extraparlamentar.

Antípoda dos posicionamentos assumidos pelo PCF, sindicatos e boa parte das organizaçôes operárias, o sequestro maoísta não prescindia do avanço sobre a frente ideológica, o que significava adentar a esfera normativa consolidada historicamente pelas instituiçôes comunistas. Por isso, a necessidade de uma configuração prévia: aglomeração dos trabalhadores na fábrica, incitação de um estado passional e, quando no seu ápice, defesa aberta do sequestro. Mas as injunçóes do maoísmo francês também deixavam transparecer a própria divisão estabelecida pelo seu discurso, entre os militantes e as massas, os intelectuais e o proletariado e suas fraçóes de classe. Disso decorre o movimento de depuração que se seguiu, claramente representado pela figura dos établis, militantes que teriam ultrapassado as barreiras de classe por meio de uma entrega total à rotina dos trabalhos nas fábricas, de forma 
anônima e clandestina (DRESSEN, 1999, 2000). Convertidos em operários, suas vidas carregariam todos os sinais de uma abnegação religiosa pronunciada, seja como expiação dos antigos privilégios de classe, seja como instrumento de propagação messiânica da verdade popular entre um proletariado cada vez mais distante das suas tarefas históricas. Sob o paradigma do établissement, o trabalho elevou-se ao estatuto de "lei natural" à qual a política revolucionária deveria submeter-se (DRESSEN, 1999, p. 195). A divisão entre massas e maoístas foi aprofundada e transposta para os processos de subjetivação individual e coletiva, na esfera laboral das fábricas. Como para outros grupos da esquerda extraparlamentar da época, subjacente aos jargóes marxistas e à apaixonada recepção das lutas no Extremo Oriente e nas franjas terceiromundistas ao sul, novos terrenos se descortinavam para a açáo direta. Com o établissement, o maoísmo havia escolhido o seu: a autocrítica militante e a depuração subjetiva pelo trabalho.

Os maoístas da École Normale que se aproximaram de Lacan estiveram distantes da entrega exigida pelo établissement e tampouco se lançaram a qualquer experiência que lembrasse tamanho comprometimento subjetivo. Ainda que alguns tenham flertado com o terrorismo (ROUDINESCO, 1986), eles pertenciam ao estrato do maoísmo que logo confessaria sua origem social e os trajetos de seus capitais culturais, forjados nos ideais da erudição e, portanto, muito mais engrenados ao maquinismo teórico do que à radicalidade evocada pela prática política implicada no confronto concreto e hostil entre classes. Talvez as contradiçóes do maoísmo normalien forneçam mais elementos explicativos para um fenômeno intelectual sem igual até a Segunda Guerra, do qual a psicanálise francesa participaria com o lacanismo, a saber, a combinação de duas vertentes historicamente independentes: a tradição da epistemologia e as correntes filosóficas centradas na existência (FOUCAULT, 2001, p. 1583). Sua institucionalização como região teórica autônoma dependeria do surgimento e consolidação de uma terceira vertente, as Ciências Humanas, forasteira e em conflito com a Filosofia (BALIBAR; DUROUX, 2012). Sem considerar as coordenadas mínimas dessa geografia, não haveria como compreender as querelas do estruturalismo, sua posterior politização e, por fim, a impostaçáo vanguardista em torno das disputas pelo seu legado; a emergência tipicamente francesa de um marxismo inspirado na diacronia da linguagem estaria fadada a ser, ao lado de tantas outras prerrogativas intelectuais da época, um evento disperso e não uma figura reluzente de um conjunto interdependente de problemas e conceitos (MANIGLIER 2011). A centralidade das Ciências Humanas caracterizou uma perspectiva crítica da 
normatização do pensamento francês, no final dos anos 1960 e sobretudo a partir do início da década seguinte. Nesse sentido, é como a integral das respectivas funções do seu "momento filosófico" que as contradiçôes do "gauchismo” propiciam cálculos e autorizam composiçóes heterodoxas. Entre o logicismo manifesto de Les Cahiers pour l'analyse e o materialismo lacaniano do "objeto $a$ ", uma autêntica existência do conceito. De um lado, o établissement como metáfora real da pulsão e seus destinos: fixação mística do trabalho, reversão da penitência em sacralização do operário, identificação subjetiva com o vazio da depuração total. Do outro, o "passe" como paráfrase maoísta: transferência com o inconsciente, trabalho permanente sobre a experiência, passagem da subjetividade a objeto fantasmático, porém, sem os riscos de alienação patológica.

A se observar pelo estilo de interlocução de Lacan com atores externos ao meio psicanalítico, a EFP terminaria por assimilar o impacto político da circulação massificada de suas ideias. A despeito do "passe" ter incitado a transformaçáo da estrutura de poder da Escola, faltavam à teoria lacaniana recursos que procedessem ao desembarque de suas categorias e conceitos, inicialmente clínicos, no continente das Ciências Humanas e, principalmente, nas faixas ocupadas pelo "gauchismo" e que eram, naquele momento, também de onde provinham os aderentes e alunos nos quais Lacan reconhecia a possibilidade da continuidade da experiência freudiana, em um mundo submetido cada vez mais à avassaladora unificação entre ciência e mercado. A teoria lacaniana dos discursos foi a resposta a esse diagnóstico. Apresentada após os levantes de 68, ela consistia em uma aplicaçáo de quatro categorias de autoria do próprio Lacan, originárias de contextos teóricos bem diferentes: o "sujeito dividido", o "significante-mestre", o "saber" e o "objeto $a$ ". A aplicação promovia uma interpretação peculiar e dinâmica do estruturalismo. Peculiar, porque conferia à estrutura do discurso uma forma gramatical, ou seja, articulava um sujeito a um modo de predicação; e dinâmica, na medida em que a lógica dos pares de oposição foi subsumida pelas posiçôes relacionais com valor de função, variável conforme a categoria predicada e a dominância consequente. Assim, se a dominância fosse gerada pelo "sujeito dividido", o discurso modulado seria o da "histeria". Caso o "significante-mestre" ocupasse o lugar de agente, o resultado seria o "discurso do mestre". Como efeito da prevalência do "saber", o "discurso universitário", e do "objeto $a$ ", o "discurso analítico".

A tradução e a congregação de categorias e conceitos, propostos em momentos diferentes, em uma teoria dos discursos, aumentavam a área de 
contato entre a psicanálise e a conjuntura política, o que também acentuava a exposição da EFP a fatores exógenos ao lacanismo, porque cada discurso equivaleria a um tipo específico de "laço social". Do ponto de vista clínico, cada qual corresponderia a um imperativo pulsional. Se, no registro de sua Escola, Lacan demonstrava interesse e abertura à movimentação social levantada pelos motins de maio, no plano teórico, por sua vez, ele se revelava reativo e disposto a contrariar até mesmo iniciativas apoiadas no lacanismo, como era o caso da reforma psiquiátrica de "setor" . Essa seria a forma oxímora de sua presença pública, manifestada em diversas ocasióes, em especial através de declaraçóes e análises sobre 68. Convidado pelo jornal Le Monde a emitir opinião sobre a reforma psiquiátrica em vias de implantação, Lacan contraria a ideia de que maio teria representado uma singularidade histórica, qualificando-o como efeito de uma predominância discursiva própria da conjunção entre ciência e mercado. Com o recurso do que em poucos meses serviria de matéria para a sua teoria dos discursos, Lacan identificará na "memorização de maio" ("maimorisation") os traços de outros eventos históricos, desde a polêmica instaurada pelos estudantes de Vincennes em favor da alteração da atribuição dos créditos para obtenção do diploma até o extremo absoluto dos campos nazistas de concentração, todos passíveis de serem colocados em série, porque submetidos a uma mesma injunção pulsional, medrada pelo mercado e prometida pela ciência (LACAN, 2008a, p. 187).

Ao reduzir os eventos de 68 a efeito de um discurso, a teoria lacaniana aprofunda as premissas do estruturalismo, identifica e objetiva a sincronia da linguagem, para projetá-la sobre a atualidade dos fenômenos políticos. Nenhum intelectual havia ousado tanto e de modo tão explicitamente anacrônico. Dos estertores do primado da estrutura, condenada às querelas de uma disputa em estado terminal, Lacan subtrai a base de sua teoria dos discursos que, ao invés de circunscrever a descontinuidade dos eventos, procedia à formalização do que os estruturalistas haviam descoberto, mas suspendido em suas pesquisas, a saber, a gramática material sob a temporalidade da história. Um discurso seria, assim, a objetivação social dessa gramática, não à toa formalizada como uma fantasia inconsciente. Os motins estudantis ocupariam o centro de um furo ("trou") sem bordas, exatamente a imagem que Lacan havia dado à topologia do "objeto $a$ ". Da mesma forma como na estrutura da angústia, seu lugar resultaria de uma mesma operação, a de ocupar o vazio com um buraco. Porém, isso não sem introduzir,

\footnotetext{
${ }^{9}$ Sobretudo a discussão introduzida pelos psicanalistas da Clínica de La Borde, Félix Guattari e Jean Oury, membros assíduos no início da EFP. Sobre a política do "setor", ver CENTRE D’ÉTUDES, DE RECHERCHES ET DE FORMATION INSTITUTIONNELLES (1975).
} 
ao mesmo tempo, uma modulação da repetição inconsciente e, portanto, uma fixação pulsional que definiria o sujeito na fantasia. Sob o impacto de 68, Lacan deslocaria o problema freudiano da pulsão de morte para o espaço gramatical do discurso. De um estruturalismo das posiçóes topologicamente reversíveis até o materialismo "real" do "objeto $a$ ", a teoria lacaniana passaria a ser uma figura da discursividade movida pela EFP. Integrada à formação analítica pelo "passe", a interrogação sobre a "ética da psicanálise" subverteu-se, ao ser cristalizada em um dos quatro tipos previstos pela teoria dos discursos. Desse ponto em diante, o lacanismo designaria náo apenas uma teoria e nem mesmo suas instituiçóes, mas, antes de tudo, um laço social determinado pela prevalência da ação do "objeto $a$ ", o "discurso analítico". A irrupção estudantil nas ruas, ainda segundo Lacan, teria revelado justamente a hegemonia desse objeto, um modo homólogo, todavia, de consequências invertidas, ao da incidência da psicanálise sobre o inconsciente. Daí maio não ter sido um sintoma social. Entre as brechas, a expressão "real" da objetividade fantasmática da história contemporânea, cujo funcionamento somente sua psicanálise poderia decifrar (LACAN, 1992, p. 98).

As quatro categorias que compóem a teoria dos discursos foram identificadas, na atmosfera política instituída por 68 , como partes de uma "álgebra”. Afora as imprecisóes de praxe que costumavam resultar de seu estilo de bricoleur, Lacan assim propôs porque, na mesma direção dos postulados de seu materialismo, o estatuto epistemológico do conceito estaria inabilitado a prover recursos que tocassem o "real" da fantasia. Por isso, a defesa da "letra", de seu registro puramente sintático que, por intermédio de uma aplicaçáo algébrica, indexaria o "saber textual" do inconsciente, àquela altura do ensino lacaniano já compreendido como opaco a toda representação ou expressão teórica. De acordo com essa aplicaçáo, o saber como "meio de gozo" implicaria sua própria disjunção com a "verdade" e o "trabalho", seja ele analítico, político, científico ou transferencial (LACAN, 1992, p. 74-75). A fantasia seria ela mesma um saber sobre a satisfaçáo pulsional do sujeito, mas com a condição de dissociá-la do "trabalho", e sob a redução da "verdade" à "letra". Nas universidades, de onde se irradiavam os protestos, o engendramento discursivo era causado pela demanda dirigida aos estudantes. Demanda, lembrará Lacan, de mais trabalho ou de mais gozo, donde a analogia entre o "objeto $a$ " e a mais-valia marxiana. Consequentemente, já que impossível de ser satisfeita, a demanda produz efeitos de divisão no sujeito que recalca a determinaçáo do saber produzido. A partir dos motins e da iconoclastia espraiada, o discurso da insurgência revelaria sua prevalência fantasmática 
através da convocação inconsciente de um "mestre". ${ }^{10} \mathrm{O}$ imperativo científico ("continue a saber mais") fixaria os estudantes no escoadouro da repetição, no vazio "real" do "objeto $a$ ", transferindo para a política de 68 a impotência de sua verdade. $\mathrm{O}$ mesmo poderia ser dito para o ensino psicanalítico. A transmissão do saber inconsciente não poderia ser confundida com o ensino, dada sua dependência em relação ao "discurso analítico", ou seja, ao "[...] ato que ordena que a causa do desejo seja o agente do discurso." (LACAN, 2003a, p. 309). Contudo, a garantia da transmissão náo poderia ser outra senáo a própria Escola que, mediante o "passe", problematizaria a reponsabilidade do analista em "[...] tornar-se psicanalista de sua própria experiência." (LACAN, 2003f, p. 248). Entre o ensino e a Escola, as inquietaçôes de uma doutrina cindida pelos efeitos de retorno da conversão da teoria em discurso:

Nosso discurso não se sustentaria se o saber exigisse a intermediação do ensino. Daí o interesse do antagonismo que enfatizo aqui entre o ensino e o saber. Não obstante, é sobre a relação entre o saber e a verdade que nosso discurso levanta a questão, por não poder resolvê-la senão pelos caminhos da ciência, isto é, do saber do mestre.

É nisso que a maneira como a verdade se formaliza na ciência, ou seja, a lógica formal, é para nós um ponto visado, por termos que estendê-la à estrutura da linguagem. Sabe-se que está aí o núcleo de onde procede meu discurso.

É preciso saber se esse discurso cai nas malhas do ensino.

Uma vez que, em suma, trata-se de apenas disso: do embaraço que meu ensino causa na Escola.

Porque os que dele se apoderam haveriam de nele introduzir apenas, ao gosto ou à vontade de outros apóstolos, um palavrório emprestado.

Será que se trata de intimar alguém a comprovar a força de convicção do que ele expressa? Na verdade, quem se faria testemunha do acento enfático da verdade? (LACAN, 2003a, p. 308).

Em carta de Lacan, datada de 1973, a três psicanalistas italianos que alimentavam a ideia de inaugurar uma escola filiada à EFP, em seu país, o analista ganha figura como sujeito de um "desejo inédito", "levado ao entusiasmo" por

\footnotetext{
10 "Se tiverem um pouco de paciência, e se aceitassem que nossos improvisos continuassem, eu lhes diria que a aspiração revolucionária só tem uma chance, a de culminar, sempre, no discurso do mestre. Isto é o que a experiência provou. É ao que vocês aspiram como revolucionários, a um mestre. Vocês o terão." (LACAN, 1992, p. 196).
} 
dar corpo ao "rebotalho" da verdade (LACAN, 2003e, p. 313-315). Nem o final de análise, nem a transposição da fantasia seriam condiçóes suficientes para o seu reconhecimento. Novamente, caberia ao "passe" a tarefa de recompor as dinâmicas de poder na Escola, de fornecer a matéria e os limites dos debates, as vias de descarga da agressividade transferencial produzida como uma espécie de detrito pulsional da instituição. O dispositivo falhará em todas tarefas, reforçando o início de um novo ciclo de formalização teórica que, ainda mais intensificada, levará a Escola a um insulamento irrecuperável e o lacanismo a um dogmatismo refém das decifrações da "álgebra", "matemas", "nós" de seu próprio discurso, vicissitudes ainda hoje observáveis em suas instituiçóes (OTA, 2011). Entretanto, na contracorrente doutrinal representada pela carta de Lacan aos italianos, a função dos recursos de formalização seria a de permitir uma incidência sobre o saber inconsciente, a partir justamente de sua impossibilidade em enunciá-lo (LACAN, 2003e, p. 315). Na última volta de seu torniquete, Lacan desejou ecoar nas assembleias e corredores de sua Escola a tese de que a eficácia psicanalítica estaria fincada nas fissuras do "simbólico", única realidade metapsicológica capaz de produzir a modificação do "real" da posição fantasmática. Curiosa ratificação, sob a vestimenta vanguardista de uma ambição soberana, do velho e conhecido princípio da talking cure freudiana.

OTA, Nilton Ken. Psychoanalysis as a political paraphrase: the École Freudienne de Paris and the Lacanian 'ethification' of theory. Trans/form/ação, Marília, v. 39, n. 4, p.59-84, Out./Dez., 2016.

\begin{abstract}
To a great extent the studies of the constitution of the Lacanism theoretical framework have occurred off the examination of its historicity. This neglect strengthens the concealment of the social process that led the Lacanian production to a deep integration between the theory formalization and the theory ethification. This process can not be understood without grasping the context of the political environment that surrounded the proposal and the existence of École Freudienne de Paris (EFP), founded by Lacan in 1964. The close contact with the young militants of the extra-parliamentary left groups of the time, notably the Maoists, and the assimilation of the problems they rose made the Lacanian thought and EFP the place of objectification of a speech moved by the political paraphrase and their engagement effects. This article aims to expose the lines of political and social structure of concepts forged by Lacan through the establishment and consolidation of his School.
\end{abstract}

KEYWORDS: May 68. Psychoanalysis. French Maoism. Intellectuals. Engagement. 


\section{REFERÊNCIAS}

ALTHUSSER, L. Écrits sur la psychanalys: Freud et Lacan. Paris: Stock ; IMEC, 1993. 2000. p. 47-71.

Freud e Lacan. In: Freud e Lacan, Marx e Freud. Rio de Janeiro: Graal,

BALIBAR, E. ; DUROUX, Y. Une conjoncture philosophique: un entretien avec Étienne Balibar et Yves Duroux [traduzido como 'A Philosophical Conjuncture': An Interview with Étienne Balibar and Yves Duroux, na versão inglesa]. In : HALLWARD, P. ; PEDEN, K. (Org.). Concept and form, interviews and essays on The Cahiers pour l'analyse. London: Verso, 2012. V. 2.

BIBLIOTHÈQUE DE DOCUMENTATION INTERNATIONALE CONTEMPORAINE. Fonds Gauche Prolétarienne. F delta rés 576 3/3/2. Trata-se de um documento sem data certa (provavelmente de 1970).

CENTRE D'ÉTUDES, DE RECHERCHES ET DE FORMATION INSTITUTIONNELLES. Histoire de la psychiatrie de secteur ou le secteur impossible? Recherches, n.17, mars 1975.

DONZELOT, J. L'invention du social. Paris: Éditions du Seuil, 1994.

DOSSE, F. História do estruturalismo, v. I: O campo do signo. Bauru: EDUSC, 2007.

DRESSEN, M. De l'amphi à l'établi : les étudiants maoïstes à l'usine (1967-1989). Paris : Belin, 1999.

Les établis, la chaîne et le syndicat : évolution des pratiques, mythes et croyances d'une population d'établis maoïstes, 1968 - 1982, monographie d'une usine Lyonnaise. Paris: L'Harmattan, 2000.

FOUCAULT, M. La vie: l'expérience et la science. In : Dits et écrits II (19761988). Paris: Quarto/Gallimard, 2001.

FREUD, S. Analisis terminable e interminable. In: . Obras completas. Madrid: Biblioteca Nueva, 1981a [1937].Tomo III.

. El 'yo' y el 'ello'. In: Obras completas. Madrid: Biblioteca Nueva, 1981b [1923].Tomo III.

. Inhibición, síntoma y angustia. In: . Obras completas. Madrid: Biblioteca Nueva, 1981c [1925]. Tomo III.

. La represion. In: - Obras completas. Madrid: Biblioteca Nueva, 1981d [1915].Tomo III.

El porvenir de una ilusion. In: . Obras completas. Madrid: Biblioteca Nueva, 1985a [1927]. Tomo III.

Fetichismo. In: Obras completas. Madrid: Biblioteca Nueva, 1985b [1927]. Tomo III. 
. Más allá del principio del placer. In: Obras completas. Madrid: Biblioteca Nueva, Madri, 1985c [1920]. Tomo III.

Pegan a un niño : aportacion al conocimiento de la génesis de las pervesiones sexuales. In: Obras completas. Madrid: Biblioteca Nueva, 1985d [1919]. Tomo III.

. Proyecto de una psicología para neurólogos. In: . Obras completas. Madrid: Biblioteca Nueva1985e [1895]. Tomo I.

. Tres ensayos para una teoría sexual. In: Obras completas. Madrid: Biblioteca Nueva, 1985f [1905]. Tomo II.

GOBILLE, B. La guerre de Change contre la 'dictature structuraliste' de Tel Quel : le 'Théorisme' des avant-gardes littéraires à l'éprouve de la crise politique de mai 68. Raisons Politiques, Paris, n.18, p. 73-96, 2005.

LACAN, J. La Science et la vérité. Les Cahiers pour l'Analyse, n. 1, p. 6-28, jan.-fév. 1966 a. Le temps logique et l'assertion de certitude anticipée. In: Écrits. Paris: Éditions du Seuil, 1966b. p. 197-213. $829-850$.

Position de l'inconscient. In: . Écrits. Paris : Éditions du Seuil, 1966c. p.

. O seminário: o avesso da psicanálise. Rio de Janeiro: Jorge Zahar, 1992. Livro 17. . O seminário: a ética da psicanálise. Rio de Janeiro: Jorge Zahar, 1997. Livro 7. . A ciência e a verdade. In: . Escritos. Rio de Janeiro: Jorge Zahar, 1998a. p. 869-892.

- O seminário: os quatro conceitos fundamentais da psicanálise. Rio de Janeiro: Jorge Zahar, 1998b. Livro 11.

. Alocução sobre o ensino. In: Outros escritos. Rio de Janeiro: Jorge Zahar, 2003a. p. 302-310.

. Ato de fundação. In: Outros Escritos. Rio de Janeiro: Jorge Zahar, $2003 \mathrm{~b}$. p. 235-247.

. Da psicanálise em suas relaçóes com a realidade. In: Outros escritos. Rio de Janeiro: Jorge Zahar, 2003c. p. 93-103.

. Discurso na Escola Freudiana de Paris. In: Outros Escritos. Rio de Janeiro: Jorge Zahar, 2003d. p. 265-287.

Nota italiana. In: . Outros escritos. Rio de Janeiro: Jorge Zahar, 2003e. p. 311-315.

. Proposição de 9 de outubro de 1967. In: Outros escritos. Rio de Janeiro: Jorge Zahar, 2003f. p. 248-267. 
Zahar, 2005a. p. 55-87.

. O seminário: a angústia. Rio de Janeiro: Jorge Zahar, 2005b. Livro 10.

. D’une reforme dans son trou. Figures de la Psychanalyse, n. 17, p. 181-187, 2008a.

. O mito individual do neurótico. Rio de Janeiro: Jorge Zahar, 2008b.

LÉVI-STRAUSS, C. O Pensamento selvagem. Campinas: Papirus, 1997.

MANIGLIER, P. (Dir.). Le moment philosophique des années 1960 en France. Paris: Presses Universitaires de France, 2011.

MATONTI, F. La politisation du structuralisme : une crise dans la théorie. Raisons Politiques, Paris, n.18, p. 49-71, 2005.

MILlER, J-A. Avertissement. Les Cahiers Pour L’Analyse, v.1, jan. 1966. Disponível em : $<$ http://cahiers.kingston.ac.uk/pdf/cpal.introduction.pdf>. Acesso em : 20 maio 2015.

OTA, N. K. O social e suas vicissitudes na psicanálise lacaniana. Tempo Social: Revista de Sociologia da USP, v. 23, n.1, p. 137-165, 2011.

PUDAL, B. ; PENNETIER, C. (Dir.). Autobiographies, autocritiques, aveux dans le monde communiste. Paris: Belin, 2002.

Le sujet communiste, identités militantes et laboratoires $d u$ «moi». Rennes: Presses Universitaires de Rennes, 2014.

ROUDINESCO, E. História da psicanálise na França: a batalha dos cem anos: 1925-1985. Rio de Janeiro: Jorge Zahar, 1986. V. 2.

SARTRE, J. P. Critique de la raison dialectique. Paris: Gallimard, 1960. Tome I.

SAWICKI, F. ; LEFEBVRE, R. La société des socialistes : le PS aujourd'hui. Paris: Éditions du Croquant, 2006.

SOMMIER, I. La violence politique et son deuil l'après 68 en France et en Italie. Rennes: Presses Universitaires de Rennes, 2008a.

. La violence révolutionnaire. Paris: Presses de la Fondation Nationale des Sciences Politiques, 2008b.

Recebido em 30/01/2016

Aceito em 18/05/2016 